\title{
Characterization of antitumor immunization to a defined melanoma antigen using genetically engineered murine dendritic cells
}

\author{
Antoni Ribas, ${ }^{1}$ Lisa H. Butterfield, ${ }^{1}$ William H. McBride, ${ }^{2}$ Vivian B. Dissette, ${ }^{1}$ Andrew Koh, ${ }^{1}$ \\ Charles M. Vollmer, ${ }^{1}$ Billy Hu, ${ }^{1}$ Angela Y. Chen, ${ }^{1}$ John A. Glaspy, ${ }^{3}$ and James S. Economou ${ }^{1}$ \\ Divisions of ${ }^{1}$ Surgical Oncology, ${ }^{2}$ Experimental Radiation Oncology, and ${ }^{3}$ Hematology-Oncology, University \\ of California, Los Angeles, California 90095.
}

\begin{abstract}
A murine model of dendritic cell (DC)-based genetic immunization to a defined human melanoma antigen (Ag), MART-1/Melan-A (MART-1), was developed. The MART-1 gene was stably transfected into the nonimmunogenic mouse fibrosarcoma cell line NFSA that is syngeneic in $\mathrm{C} 3 \mathrm{Hf} / \mathrm{Sem} / \mathrm{Kam}\left(\mathrm{C} 3 \mathrm{H}, \mathrm{H}-2^{\mathrm{k}}\right)$ mice to generate the NFSA(MART1) cell line. In vivo protection from a lethal NFSA(MART1) tumor challenge could be generated by DCs transduced with a recombinant adenovirus (AdV) vector expressing MART-1 (AdVMART1). This model has the following characteristics: (a) immunological specificity and memory, (b) comparable protection for varying transduction multiplicities of infection, cell doses, and sites of DC inoculation but, interestingly, worse protection with increasing numbers of vaccinations, (c) the ability to treat small established tumors, (d) an absolute requirement for CD8 and CD4 T cells, (e) generation of MART-1-specific splenic cytotoxic T lymphocytes, and (f) up-regulation of both T helper type 1 and T helper type 2 cytokines. Genetically engineered DCs presenting defined tumor Ags represent an attractive method to generate effective immune responses.
\end{abstract}

Key words: Dendritic cells; gene therapy; immunotherapy; in vivo animal models; tumor immunity.

$\mathrm{T}$ umors are often antigenic but not immunogenic and are relatively inefficient at activating antigen $(\mathrm{Ag})$ specific effector cells. ${ }^{1,2}$ Dendritic cells (DCs) are specially suited for Ag presentation due to their high level of major histocompatibility complex (MHC) class I and II expression together with the expression of costimulatory molecules. ${ }^{3}$ The presentation of tumor-associated Ags by ex vivo-expanded DCs may allow the immune system to overcome its failure to react effectively against the Ags expressed by tumor cells. ${ }^{4,5}$

MART-1 is a human melanocyte lineage-specific Ag that is expressed by a high percentage of human malignant melanomas. ${ }^{6-8}$ An animal model to test different genetic immunization strategies against the MART-1 Ag was developed, in which a nonimmunogenic mouse fibrosarcoma cell line (NFSA) was genetically engineered to express MART-1. This murine tumor system was used to study whether immunization strategies against the MART-1 Ag can inhibit or delay the growth of syngeneic tumor cells expressing MART-1 in vivo.

Received August 5, 1998; accepted December 19, 1998.

Address correspondence and reprint requests to Dr. James S. Economou, Division of Surgical Oncology, Room 54-140 CHS. UCLA School of Medicine, 10833 Le Conte Avenue, Los Angeles, CA 90095-1782. E-mail address: jeconomo@surgery.medsch.ucla.edu

(C) 1999 Stockton Press 0929-1903/99/\$12.00/+0
We have shown previously that immunization with adenovirus (AdV)-transduced DCs is superior to other genetic immunization strategies, such as intramuscular plasmid immunization or local or systemic delivery of an AdV vector carrying the MART-1 gene (AdVMART1), ${ }^{9}$ which has been corroborated in another tumor $\mathrm{Ag}$ model. ${ }^{10}$ This report expands on our previous studies using genetically engineered murine DCs to optimize the schedule of administration, treat established subcutaneous (s.c.) tumors and pulmonary metastases, and define the type of immune response generated to MART-1 in this mouse model.

\section{MATERIALS AND METHODS}

Mice and cell lines

Female $\mathrm{C} 3 \mathrm{H}$ mice $\left(\mathrm{H}-2^{\mathrm{k}}\right), 5-8$ weeks old, were bred and kept in the Animal Facility of the Department of Radiation Oncology at the University of California (Los Angeles, Calif). All animal studies were conducted in accordance with the animal care policy of the University of California and the Chancellor's Animal Research Committee. Animals were kept in a controlled flora environment and were sacrificed according to established guidelines.

NFSA is a nonimmunogenic spontaneous murine fibrosarcoma that arose in this substrain of $\mathrm{C} 3 \mathrm{H}$ mice. ${ }^{11,12}$ NFSA(MART-1) was developed by transfection of the NFSA line with a plasmid carrying $M A R T-1$ cDNA and the neo resistance gene (pRcCMVMART1) as described previously. ${ }^{9}$ SVEC- 
(MART1) was developed by pRcCMVMART1 transfection of the modified endothelial cell line SVEC. The tumor cells used in the in vivo studies were grown as s.c. tumors in $\mathrm{C} 3 \mathrm{H}$ mice and were used for tumor challenge between in vivo passages 2 and 7 (except for Fig 1a, where cells from in vitro culture were used for tumor challenge). Thereafter, mice were examined two to three times per week for tumor development and growth. The number of NFSA(MART1) cells from a singlecell suspension of in vivo-growing tumors required for tumor development in $50 \%$ of mice $\left(\mathrm{TD}_{50}\right)$ was determined using a previously established protocol. ${ }^{11}$ Briefly, groups of eight $\mathrm{C} 3 \mathrm{H}$ mice were administered s.c. injections at four sites overlying the abdomen with $1 \times 10^{4}, 5 \times 10^{4}, 1 \times 10^{5}$, and $5 \times 10^{5}$ viable tumor cells in $50 \mu \mathrm{L}$ of phosphate-buffered saline (PBS) (Mediatech, Herndon, Va). Tumor cells were obtained from a single-cell suspension of exponentially growing NFSA (MART1) tumors in in vivo tumor passage 4 in syngeneic mice. Tumor take was expressed as the $\mathrm{TD}_{50}$ value.

\section{Preparation of DCs}

The development of DCs from murine bone marrow (BM) progenitor cells was performed following the method put forth by Inaba ${ }^{13}$ with modifications. ${ }^{9}$ BM cells were cultured overnight in RPMI 1640 (Life Technologies, Gaithersburg, Md) with $10 \%$ fetal calf serum (FCS) (Gemini Products, Calabasas, Calif) and $1 \%(\mathrm{v} / \mathrm{v})$ penicillin, streptomycin, and fungizone (Gemini) in a Petri dish. Nonadherent cells were replated on day 1 at $2-3 \times 10^{6}$ cells/well in 24 -well plates with murine GM-CSF (100 ng/mL) (Amgen, Thousand Oaks, Calif) and murine interleukin-4 (IL-4) (500 U/mL) (R\&D Systems, Minneapolis, Minn). Cultures were maintained in RPMI 1640 medium containing $10 \%$ FCS and antibiotics (complete medium (CM)) at $37^{\circ} \mathrm{C}$ in $5 \% \mathrm{CO}_{2}$. On day 4 , nonadherent cells were removed by aspirating $80-90 \%$ of the media, and adherent cells were re-fed with an addition of $1 \mathrm{~mL}$ per well of $\mathrm{CM}$ plus cytokines. DCs were harvested as the loosely adherent cells from the day- 8 cultures.

\section{$A d V$ infection of murine DCs}

DCs were transduced with an E1-deleted replication-defective $\mathrm{AdV}$ vector, where the expression of the MART-1 gene is driven by the cytomegalovirus promoter/enhancer (AdVMART1), with an E1-deleted vector not carrying any gene insert (AdVRR5), or with an E1-deleted vector carrying the luciferase gene (AdVLuc). ${ }^{9,14}$ Day-8 DCs were transduced in 15 -mL conical tubes (Costar, Acton, Mass) in a final volume of $1 \mathrm{~mL}$ of RPMI 1640 with $2 \%$ FCS, to which the appropriate amount (according to the multiplicity of infection (MOI) of each study) of virus stock was added. Transduction was carried out for 2 hours at $37^{\circ} \mathrm{C}$, after which time the DCs were washed extensively and resuspended in $0.2 \mathrm{~mL}$ of PBS per animal for injection into mice. Cell counts were determined using a hemocytometer; viability was assessed by trypan blue exclusion. Viability exceeded $95 \%$ in all cases.

For an assessment of MART-1 protein expression by the DCs, the monoclonal antibody (mAb) NCL-MelanA (Novocastra, Newcastle on Tyne, UK) was used. DCs were transduced with AdVMART1 or AdVRR5 at an MOI of 100, washed extensively, and kept in a $15-\mathrm{mL}$ conical tube with $\mathrm{CM}$ plus cytokines for 48 hours. Cytospin preparations were stained with the anti-MART-1 mAb and visualized using a peroxidase substrate kit and diaminobenzidine reagent (Vector Laboratories, Burlingame, Calif) according to the manufacturer's instructions. a

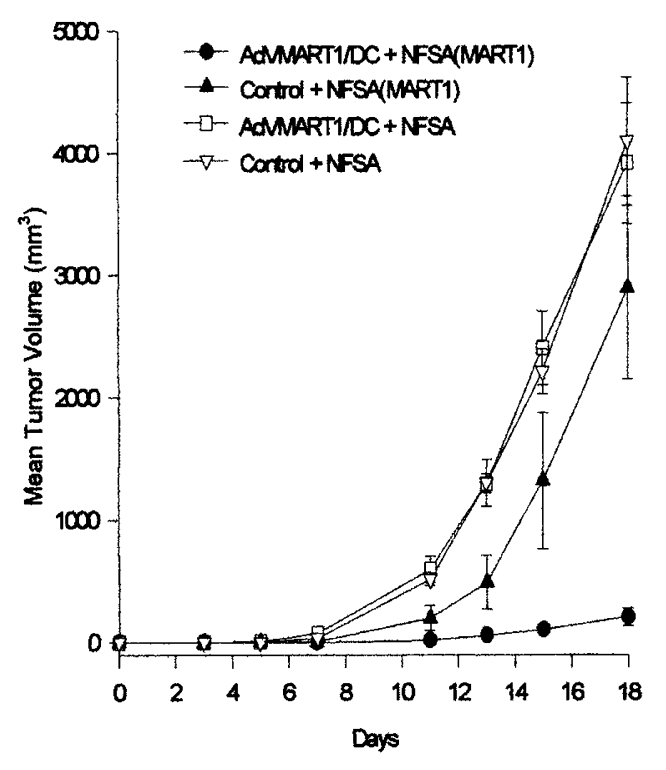

b

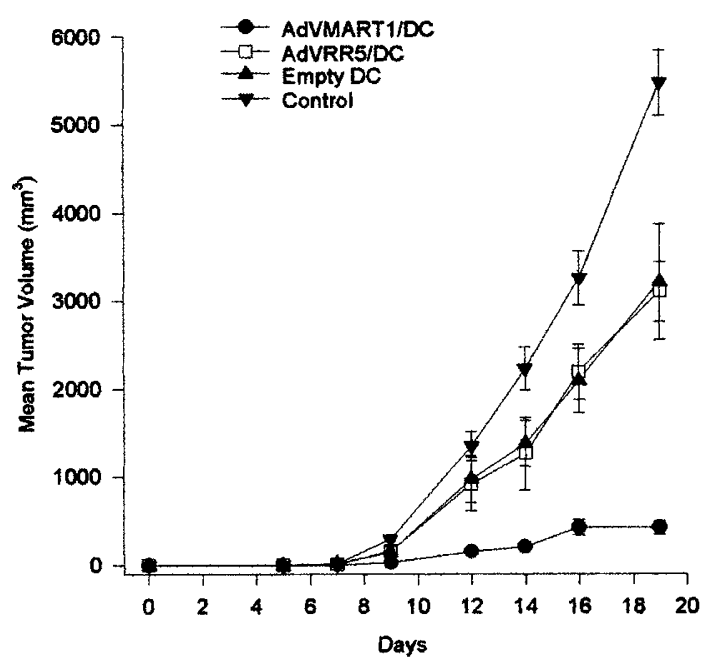

Figure 1. MART-1-specific protection with AdVMART1/DC vaccination. a: Mice were challenged with NFSA or NFSA(MART1). In mice challenged with NFSA, no differences were noted compared with a control, unimmunized group $(P=.8)$. AdVMART1/DCimmunized mice challenged with NFSA(MART1) had smaller tumors than the control group $(P=.01)$. b: Mice immunized with DCs transduced with AdVMART1 had final tumor volumes that were smaller than those for animals vaccinated with AdVRR5/DCs $(P=$ .0001), animal vaccinated with untransduced DCs $(P=.007)$, or control animals $(P=.007)$. 


\section{Flow cytometric analysis}

For a flow cytometric analysis of MHC molecule expression, NFSA(MART1) tumors were trypsinized and stained with purified supernatant from the hybridoma line 16-1-2N (HB-14, American Type Culture Collection (ATCC), Manassas, Va), which expresses an anti-H-2 ${ }^{\mathrm{k}}$ antibody $(\mathrm{Ab})$. MHC class II expression was assessed by primary staining with purified anti- $\mathrm{Ia}^{\mathrm{k}} \mathrm{Ab}$ (Becton Dickinson, Bedford, Mass). After 1 hour of incubation on ice, preparations were washed three times in PBS plus 2\% bovine serum albumin (Sigma, St. Louis, Mo) plus $0.01 \%$ sodium azide (Sigma) and stained with a fluorescein isothiocyanate-labeled goat anti-mouse secondary Ab. To assess the MHC expression in transduced and untransduced DCs, day-8 DCs were harvested and placed into $15-\mathrm{mL}$ conical tubes in $1 \mathrm{~mL}$ of $2 \%$ FCS/RPMI 1640. Next, DCs were either transduced or not transduced (empty DCs) with the AdVMART1 construct at an MOI of 100 for 2 hours. Cells were washed and resuspended in $10 \mathrm{~mL}$ of $\mathrm{CM}$ with cytokines and incubated for 72 hours at $37^{\circ} \mathrm{C}$ to allow maximum transgene expression before being stained with the MHC class I and II Abs for flow cytometric analysis.

\section{Luciferase luminometric assay}

Cultured DCs were lysed using $200 \mu \mathrm{L}$ of luciferase extraction buffer (LEB) (1\% Triton X-100, 25 mM glycyl-glycine, $15 \mathrm{mM}$ $\mathrm{MgSO}_{4}$, and $4 \mathrm{mM}$ ethyleneglycol-bis( $\beta$-aminoethyl ether)$N, N, N^{\prime}, N^{\prime}$-tetraacetic acid) and vortexed. A total of $250 \mu \mathrm{L}$ of luciferase assay buffer ( $25 \mathrm{mM}$ glycyl-glycine, $15 \mathrm{mM} \mathrm{MgSO}_{4}$, $4 \mathrm{mM}$ ethyleneglycol-bis $\left(\beta\right.$-aminoethyl ether)- $N, N, N^{\prime}, N^{\prime}$-tetraacetic acid, and $14 \mathrm{mM} \mathrm{KPO}_{4}$ ) was preloaded into $12 \times 75$ $\mathrm{mm}$ analytical luminescence cuvettes together with $1 \mathrm{mg} / \mathrm{mL}$ of equine adenosine triphosphate (Sigma), which was added at the time of luciferase reading. A total of $45 \mu \mathrm{L}$ of centrifuged supernatant from each cell lysate was added to each cuvette and placed into a Monolight 1500 luminometer (Analytical Luminescence Laboratory, Ann Arbor, Mich). Samples were run in duplicate. For organ luciferase assay, organs were harvested, homogenized, and incubated for 45 minutes in LEB at a concentration of $5 \mathrm{mg}$ organ $/ 100 \mu \mathrm{L}$ of LEB. After incubation, samples were vortexed and centrifuged at 13,000 revolutions per minute for 5 minutes. A total of $100 \mu \mathrm{L}$ of supernatant from each sample was loaded onto duplicate luminescence cuvettes containing luciferase assay buffer plus adenosine triphosphate. Results are expressed as light units per milligram of organ wet weight. ${ }^{15}$

\section{In vivo studies}

For protection studies, $\mathrm{C} 3 \mathrm{H}$ mice were immunized s.c., intraperitoneally (i.p.), or intravenously (i.v.) at weekly intervals according to each study design. Tumor challenge was performed 1 week after the last immunization with $1 \times 10^{6}$ cells per animal from a single-cell suspension from progressively growing tumors in syngeneic mice (unless stated otherwise). For the treatment of established s.c. tumors, tumor cells $(1 \times$ $10^{6}$ cells) from in vivo tumors were injected on day 0 ; animals were randomized to treatment groups at different timepoints, but always when tumors were palpable. For the pulmonary metastases model, animals received an i.v. injection of singlecell NFSA(MART1) suspensions on day 0 through the lateral tail vein and were treated with DCs on day 7.

To generate single-cell suspensions, tumors were surgically removed, decapsulated, and minced. Minced tumors underwent enzymatic digestion for 1-2 hours with deoxyribonuclease I (0.1 mg/mL, Sigma) and collagenase D (1 mg/mL, Boehring- her Mannheim, Indianapolis, Ind) in $50 \mathrm{~mL}$ of AIM-V media (Life Technologies). Viable cells were washed three times in PBS and resuspended in $0.2 \mathrm{~mL}$ of PBS per animal to be injected s.c. into the left flank or i.v. through the lateral tail vein to establish pulmonary metastases. Injected cells were $>70 \%$ viable as determined by trypan blue exclusion. The size of tumors was assessed three times weekly using calipers. In protection studies, tumors are presented as tumor volume; in studies treating established tumors, tumors are presented as tumor diameter. Tumor volume was approximated by the following calculation: 4/3 $\pi r^{3}$ ( $r=$ radius). Animals were sacrificed in all experiments when tumor measurement (length or width) was $>20 \mathrm{~mm}$. Experiments included five mice per group. In the pulmonary metastases model, mice were treated on day 7 from tumor i.v. injection, and lungs were harvested on day 15, briefly washed in water, and fixed using Bouin's solution (Sigma). The number of pulmonary metastases was counted 24 hours later.

In vivo mAb ablation of CD8 (clone 2.43, ATCC TIB 210) or CD4 (clone GK1.5, ATCC TIB 207) T-cell subsets was performed by i.p. injection on days 5, 3, and 1 before tumor inoculation, and every 6 days thereafter $(0.25 \mathrm{mg} / \mathrm{mouse} /$ injection for anti-CD4 $\mathrm{Ab}$, and $0.5 \mathrm{mg} /$ mouse/injection for anti-CD8 Ab). Ab suspensions were purified from the hybridoma supernatants and ascitic fluid of pristane-treated mice by passage through protein $\mathrm{G}$ columns according to the manufacturer's instructions (Pierce, Rockford, Ill). Eluted immunoglobulins were dialyzed against $\mathrm{PBS}$ and stored at $4^{\circ} \mathrm{C}$ at 1 $\mathrm{mg} / \mathrm{mL}$ suspensions. $\mathrm{CD}^{+}$and $\mathrm{CD}^{+}$T-cell depletion was monitored by flow cytometric analysis of splenocytes at the day of tumor challenge.

\section{Cytokine profile by reverse transcriptase polymerase chain reaction $(R T-P C R)$}

Spleens from DC-immunized or unimmunized mice were harvested, and splenocytes were released. Spleen cells were depleted of red blood cells by hypotonic lysis (ACK buffer composed of $0.15 \mathrm{M} \mathrm{NH}_{4} \mathrm{Cl}, 10 \mathrm{mM} \mathrm{KHCO}, 0.05 \mathrm{mM}$ sodium ethylenediaminetetraacetic acid), washed three times in $\mathrm{CM}$, and restimulated in vitro by culture with irradiated NFSA(MART1) tumor cells (25:1 or 100:1 responder to stimulator ratios) for 4 days without any cytokine addition. On day 5, nonadherent cells were harvested and washed twice in PBS before RNA isolation using TRIzol (Life Technologies). Each RNA sample was treated with deoxyribonuclease (Stratagene, La Jolla, Calif), reverse transcribed with random hexamer primers, and subsequently subjected to PCR with IL-2, interferon- $\gamma($ IFN- $\gamma)$, IL-4, or IL-10 PCR primers according to the manufacturer's instructions (Clontech, Palo Alto, Calif). Murine adenine phosphoribosyltransferase (APRT)-specific PCR primers were used to semiquantify the cDNA yield in each reverse-transcribed sample.

\section{Cytokine profile by enzyme-linked immunospot (ELISPOT)}

Red blood cell-depleted splenocytes were restimulated in vitro by culture with irradiated SVEC(MART1) (25:1 responder to stimulator ratio) with $10 \mathrm{U} / \mathrm{mL}$ of IL-2 for 3 days. The $96-w e l l$ mixed cellulose plates (Multiscreen filtration system, Millipore, Bedford, Mass) were coated with anti-IFN- $\gamma$ or anti-IL-4 purified $\mathrm{Ab}$ at $2 \mu \mathrm{g} / \mathrm{mL}$ (PharMingen, San Diego, Calif) and blocked with PBS plus 10\% FCS (blocking buffer) for 1 hour before adding the restimulated splenocytes. On day 4 , nonadherent cells were harvested, resuspended at $2 \times 10^{6}$ cells $/ \mathrm{mL}$ in X-Vivo 10 (BioWhittaker, Walkersville, Md), and added in 1/3 
dilutions to triplicate wells of the Ab-coated plates (final volume was $100 \mu \mathrm{L} /$ well). After 24 hours of incubation at $37^{\circ} \mathrm{C}$, plates were washed with ice-cold PBS plus Tween-20 (Fisher, Fair Lawn, NJ), $50 \mu \mathrm{L}$ of biotinylated anti-IFN- $\gamma$ or anti-IL-4 purified $\mathrm{Ab}$ at $2 \mu \mathrm{g} / \mathrm{mL}$ (PharMingen) was added to each well, and plates were incubated overnight at $4^{\circ} \mathrm{C}$. On the following day, $100 \mu \mathrm{L} /$ well of horseradish peroxidase avidin $\mathrm{D}$ (Vector) diluted $1 / 2000$ in blocking buffer was added to washed plates and incubated for 1 hour. Plates were developed by adding 150 $\mu \mathrm{L}$ of a substrate buffer containing 1 tablet $(20 \mathrm{mg})$ of 3-amino-9-ethyl-carbazole (Sigma) diluted in $2 \mathrm{~mL}$ of $N, N$ dimethyl foramide (Fisher), $48 \mathrm{~mL}$ of $0.05 \mathrm{M}$ sodium acetate buffer ( $\mathrm{pH} 4.5$ ), and $20 \mu \mathrm{L}$ of $30 \% \mathrm{H}_{2} \mathrm{O}_{2}$ (Fisher), and filtered with one 0.45 - and two $0.22-\mu \mathrm{m}$ filters (Millipore). Plates were developed for 10-15 minutes, washed with running water, and dried; spot-forming colonies were counted under a dissecting microscope. Precursor frequency was calculated as the ratio between how many restimulated cells had to be added to a well to obtain one MART-1-specific spot.

\section{Cytotoxicity assays}

Splenocytes harvested from mice 7 days after the last immunization were restimulated by coculture with irradiated NFSA(MART1) or SVEC(MART1) cells (25:1 ratio) in RPMI 1640 with $10 \%$ FCS and $10 \mathrm{U} / \mathrm{mL}$ of IL-2 (Hoffmann-La Roche, Nutley, NJ). Effector cells were harvested on day 5. Splenocytes from normal unimmunized mice served as controls and were stimulated in vitro in the same manner. For cytotoxicity assays, $2 \times 10^{6}$ target cells were labeled by incubation in 2.5 $\mathrm{mL}$ of RPMI 1640 plus $10 \%$ FCS with ${ }^{51} \mathrm{Cr}(100 \mu \mathrm{Ci})$ (Amersham Life Science, Arlington Heights, Ill) for 18 hours at $37^{\circ} \mathrm{C}$, washed extensively, and cocultured at $1 \times 10^{4}$ cells/well with effector cells (at the ratios given in the figures) in 96-well, round-bottom plates $(200 \mu \mathrm{L} /$ well) for 4 hours at $37^{\circ} \mathrm{C}$. Supernatants $(100 \mu \mathrm{L})$ from triplicate cultures were collected and counted. In mAb-MHC class I blocking experiments, $10 \mu \mathrm{L}$ of purified hybridoma ascites (16-1-2N hybridoma, ATCC) was added to chromated target cells before mixing with effector cells. For natural killer (NK) activity inhibition, $4 \times 10^{5}$ nonchromated Yac- 1 cells were added to each well to obtain a $40 \times$ excess of cold NK targets per well. Data points are expressed as the mean percentage of release of ${ }^{51} \mathrm{Cr}$ from target cells $\pm \mathrm{SEM}$.

\section{Statistical analysis}

The $\chi^{2}$ test or Fisher's exact test was used to compare categorical variables. The Student $t$ test or the Mann-Whitney rank sum test was performed to interpret the significance of differences between final tumor volumes from different groups of animals (presented as mean \pm SEM in the figures). Comparisons were performed excluding the animals that were completely protected from tumor challenge to give a reliable assessment of the effect of immunization on the tumor growth curves of animals that did develop tumors. Also, completely protected animals are presented separately from tumor-bearing animals from the same group in the figures.

\section{RESULTS}

\section{Characterization of NFSA(MART1) stable transfectant} cell line

NFSA is a spontaneously arising nonimmunogenic murine fibrosarcoma cell line. ${ }^{11}$ The in vitro and in vivo growth characteristics of the stable transfectant NFSA(MART-1) are similar to the parental line NFSA; the $\mathrm{TD}_{50}$ when using a single-cell suspension of NFSA(MART1) tumor cells prepared from an exponentially growing tumor is $\sim 4 \times 10^{4}$. Flow cytometric analysis of the expression of MHC class I molecules is unchanged after the stable transfection of NFSA with pMART-1 (data not shown). Neither cell line expresses MHC class II molecules.

\section{Adenoviral transduction of DCs}

Murine DCs were transduced with AdVMART1 with an MOI varying between 1 and 100 without adenoviral cytopathic effect. ${ }^{9}$ AdVMART1-transduced DCs (AdVMART1/DCs) express MART-1 mRNA ${ }^{9}$ and express MART-1 protein as evidenced by cytoplasmic staining with a MART-1-specific mAb (data not shown). The E3 region of this E1-deleted AdV vector is functional; Because E3 has been shown to down-regulate MHC molecule expression, ${ }^{16}$ the possible change in MHC class I and II expression in AdVMART1-transduced DCs was assessed. AdVMART1 transduction at an MOI of 100 did not alter the level of MHC class I and II expression by DCs (data not shown).

\section{MART-1-specific protection with AdVMART1/DCs}

AdVMART1/DC-immunized mice were partially protected from a tumor challenge with MART-1-expressing tumors (NFSA(MART1)) but were not protected from NFSA parental tumors (Fig 1a). Untransduced DCs or DCs transduced with an empty AdV vector (AdVRR5) resulted in a minor delay in tumor outgrowth compared with AdVMART1/DC vaccination (Fig 1b). Untransduced DCs had the same effect as AdVRR5-transduced DCs (AdVRR5/DCs), suggesting that there is an Agnonspecific effect on tumor growth. We have observed this nonspecific effect in five of eight protection studies in which groups of mice were immunized with untransduced DCs.

\section{Superiority of DCs as Ag-presenting cells (APCs)}

Cells that are able to function as effective Ag presenters include monocytes, macrophages, B cells, and DCs. Cells released from the spleen and BM contain significant numbers of these APCs and were compared with GMCSF/IL-4 in vitro-differentiated DCs. In addition, the MART-1 Ag-presenting ability of NFSA(MART1) cells was assessed by vaccinating mice with irradiated (30 Gy) NFSA(MART1). AdVMART1/DCs elicited greater antitumor protection to NFSA(MART1) tumor challenge compared with vaccination with the other cell types transduced with the same AdV vector (Fig 2). Immunization with irradiated NFSA(MART1) cells did not generate significant antitumor protection against a NFSA(MART1) tumor challenge, suggesting that this stable transfectant cell line expressing a human tumor $\mathrm{Ag}$ is, at best, weakly immunogenic. 


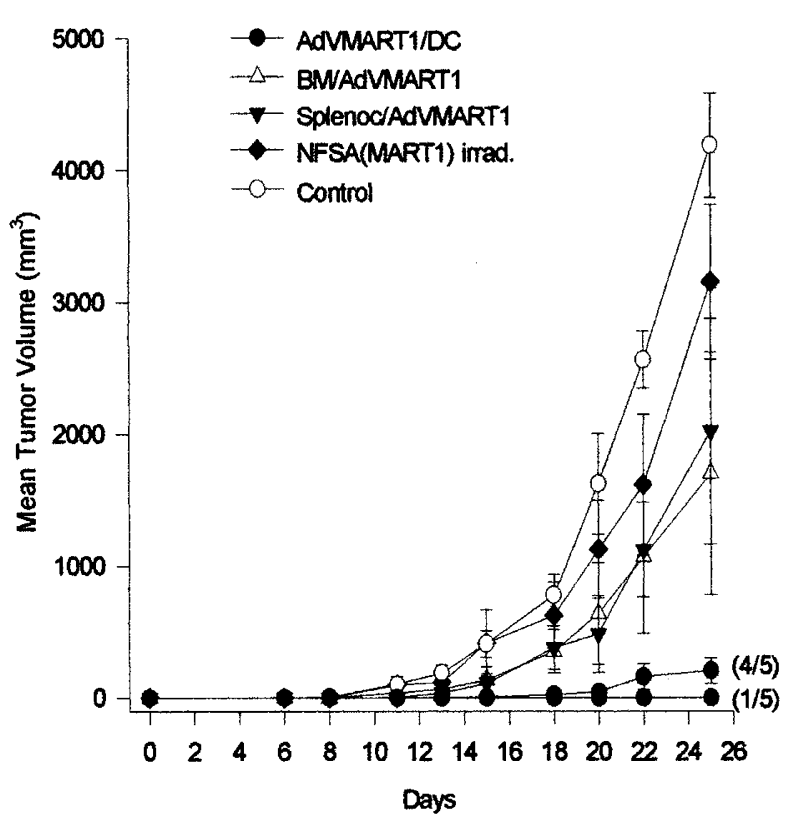

Figure 2. Superior Ag presentation by DCs. Mice were vaccinated with different cell types expressing MART-1. AdVMART1/DC vaccination yielded superior antitumor protection compared with AdVMART1-transduced BM cells ( $P=.03)$, AdVMART1-transduced spleen cells (0.01), and irradiated NFSA(MART1) cells $(P=.001)$. No significant differences were observed between control mice and mice immunized with irradiated NFSA(MART1) $(P=.1)$.

\section{Effective antitumor protection using} MART-1-transduced DCs

The ability of adenovirally transduced DCs to genetically immunize against a tumor challenge with MART-1expressing tumor cells was assessed in a series of successive studies, in which $5 \times 10^{5}$ DCs transduced with AdVMART1 at an MOI of 100 were injected i.v. at two weekly intervals. Each study contained control groups of nonimmunized mice, all of which developed tumors. Overall, complete protection from tumor challenge with NFSA(MART-1) in 24 in vivo studies using the same immunization schedule was achieved in $21 \%$ of mice (95\% confidence interval, 17-25\%; $P<.0001$ when compared with protection in the control group, Table 1). Immunological memory developed in these mice and lasted for $\geq 4$ months. A total of 8 of $11(73 \%)$ mice protected from the first tumor challenge were able to reject a subsequent tumor challenge 1-2 months later. Protection waned after $>4$ months, with only $30 \%$ of mice rejecting challenge (Table 1 ).

\section{Optimization of AdVMART1/DC immunization protocol}

Several studies were performed to define the optimal in vivo immunization strategy with MART-1 genetically engineered DCs. Immunization with $1 \times 10^{6}$ or $5 \times 10^{5}$ AdVMART1/DCs per vaccination generated similar protection. There was a trend toward lower protection with $1 \times 10^{5}$ DCs (Fig 3a). No significant differences
Table 1. Number of Animals Completely Protected from the First or the Second Tumor Challenge with NFSA(MART1)

\begin{tabular}{lrll}
\hline & \multicolumn{3}{c}{ Tumor protection } \\
\cline { 2 - 4 } & AdVMART1/DCs & Control & $P$ \\
\hline First challenge & $25 / 119(21 \%)$ & $0 / 119$ & $<0.0001$ \\
Rechallenge ( $<2$ months) & $8 / 11(73 \%)$ & $0 / 5$ & 0.01 \\
Rechallenge (2-4 months) & $2 / 4(50 \%)$ & $0 / 5$ & 0.1 \\
Rechallenge ( $>4$ months) & $3 / 10(30 \%)$ & $0 / 5$ & 0.5 \\
\hline
\end{tabular}

In 24 in vivo studies, groups of five animals vaccinated with two i.v. injections of $5 \times 10^{5}$ AdVMART1/DCs were challenged with a s.c. injection of $1 \times 10^{6} \mathrm{NFSA}(\mathrm{MART} 1)$ cells. Mice that rejected the first tumor challenge were rechallenged with the same amount of tumor cells. At the time of rechallenge, mice had been followed for different periods of time (range: 1-10 months). Tumor appearance is compared with control, unimmunized mice challenged at the same time.

were noted when mice were immunized one or three times, but animals receiving five vaccinations had poorer protection (Fig 3b). A similar trend toward better protection with fewer immunizations was observed in a series of three similar studies (data not shown). In three separate studies, the in vivo effect of transducing DCs at different MOIs was assessed. No consistent differences in antitumor protection were observed with MOIs of 3, 30, or 100 (Fig 3c). In two separate studies, an i.v. injection of DCs yielded similar antitumor protection compared with i.p. and s.c. injections (Fig 3d).

\section{In vivo detection of $D C s$}

DCs administered s.c. or i.v. yielded similar antitumor protection, but their in vivo distribution was likely to differ. Therefore, the organ distribution of injected DCs was determined. DCs were transduced with the AdVLuc reporter gene vector and injected i.v. or s.c.; various organs were assayed for luciferase expression 24 hours later. As shown in Figure 4, DCs injected i.v. were found primarily in the lungs, with some also present in the spleen. Following s.c. injection, most of the transduced cells remained at the injection site, with some detected in the ipsilateral popliteal draining lymph nodes (LNs). Contralateral LNs and other lymphoid organs (spleen and thymus) did not have luciferase expression. In a separate experiment, similar results were obtained when assaying luciferase expression 48 hours after DC injection (data not shown). In summary, DCs injected i.v. localize in the lungs and spleen, whereas DCs injected s.c. drain to the regional LNs.

\section{Treatment of established palpable s.c. tumors}

NFSA(MART1) tumors were established s.c. in $\mathrm{C} 3 \mathrm{H}$ mice and allowed to grow until they were measurable. On the day of DC treatment, animals with similarly sized tumors were randomized into groups of five. AdVMART1/DC treatment altered the tumor growth curve of animals with tumors ranging in size from 1.5 to 


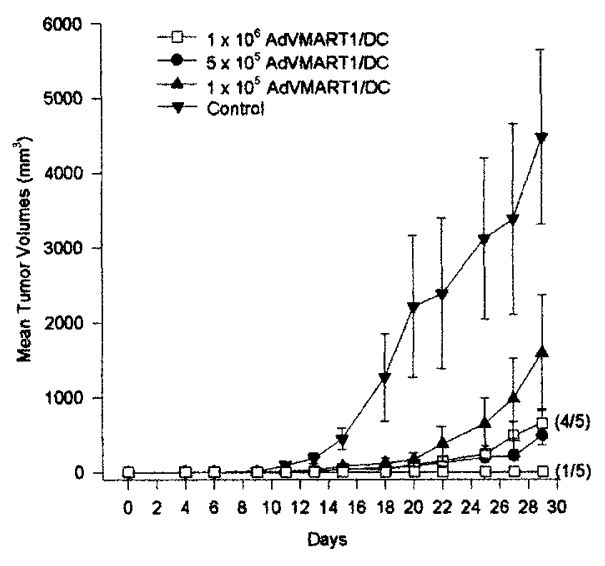

c

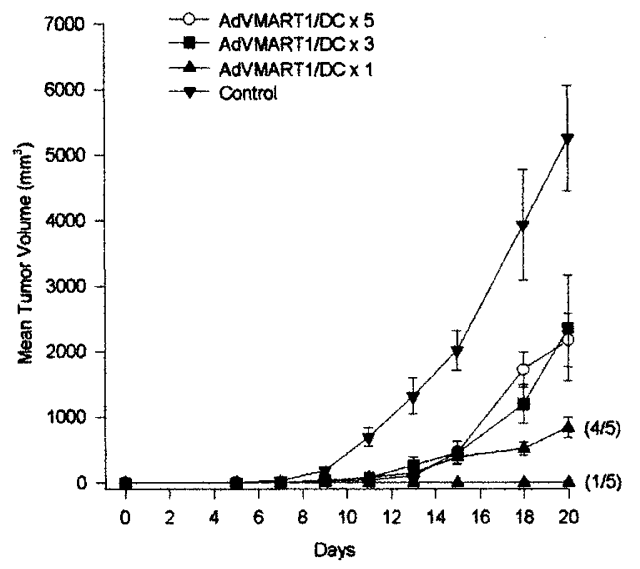

$\mathrm{d}$
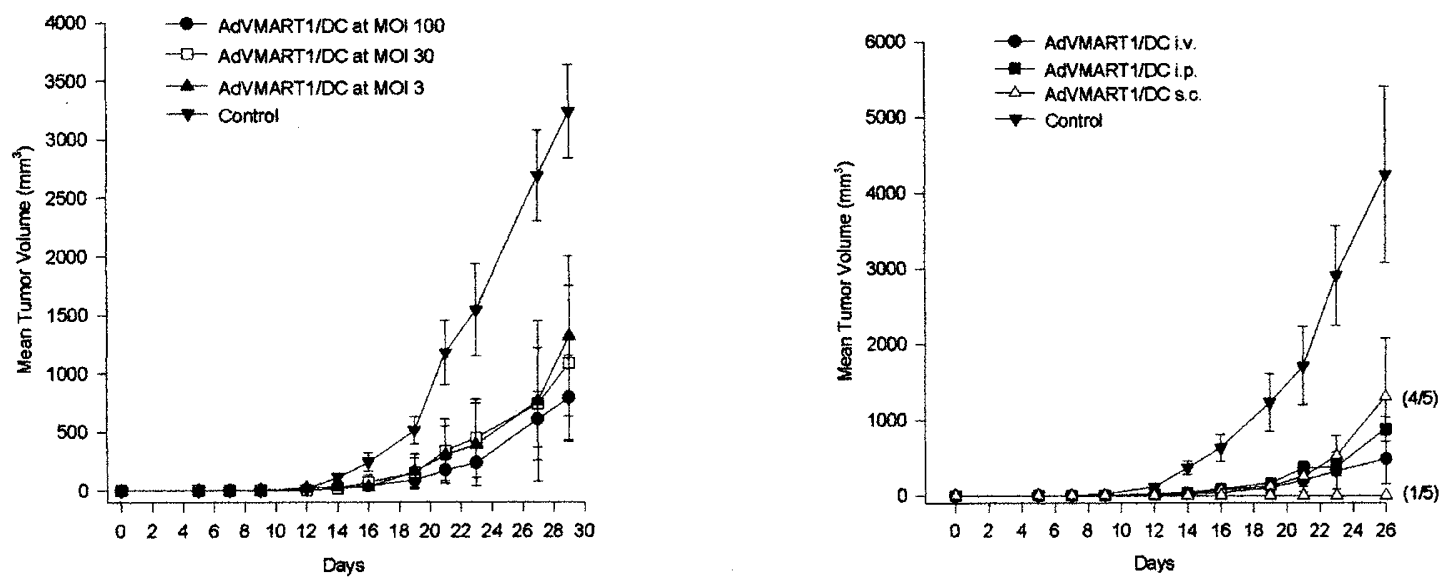

Figure 3. Influence of the vaccination schedule on antitumor protection. a: Effect of the number of DCs per vaccination. Mice were immunized twice i.v. with $1 \times 10^{5}, 5 \times 10^{5}$, or $1 \times 10^{6}$ AdVMART1/DCs. Significant differences were found between the control group and animals immunized with $5 \times 10^{5}$ and $1 \times 10^{6} \mathrm{DCs}\left(P=.01\right.$ in both cases); marginal differences were found with the group immunized with $1 \times 10^{5}$ DCs $(P=.07)$. No significant differences were observed between immunizing with $1 \times 10^{5} \mathrm{DCs}$ and the other two immunized groups $(P>.1)$. b: Effect of the number of immunizations. Mice were immunized one, three, or five times. Final tumor volumes compared with a control, unimmunized group yielded significant differences in all cases $(P=.01)$. Also, significant differences were noted between animals receiving one and five vaccinations $(P=.01)$, whereas differences between animals receiving one and three vaccinations did not reach statistical significance $(P=$ .2). c: Effect of the MOI used to transduce the DCs. Compared with a control, unimmunized group, significant differences were found with an MOI of $100(P=.001)$. In this study, immunization with DCs transduced at MOls of 3 and 30 did not yield statistically significant differences compared with the control group. However in two other studies, DCs transduced at MOls of $<100$ yielded significant differences compared with the control group (study 1: MOI of 1 versus control, $P=.008$; MOI of 10 versus control, $P=.003$. study 2 : MOl of 3 versus control, $P=.005 ; \mathrm{MOl}$ of 30 versus control, $P=.01)$. d: Effect of the route of immunization. Mice were immunized i.v., s.c., or i.p. Final tumor volumes compared with a control, unimmunized group yielded significant differences with animals immunized i.v. $(P=.008)$, s.c. $(P=.04)$, and i.p. $(P=.02)$. 


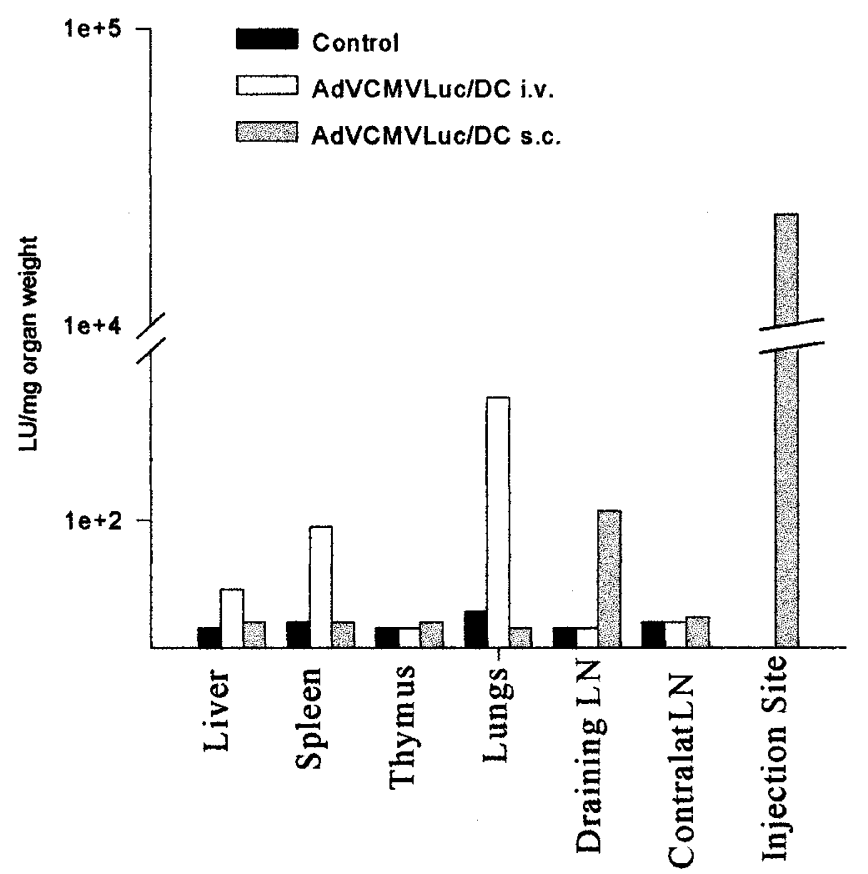

Figure 4. In vivo detection of DCs administered i.v. or s.c. DCs were transduced with AdVCMVLuc at an MOI of 100. After extensive washing, transduced DCs $\left(1 \times 10^{6} /\right.$ animal $)$ were injected i.v. into the lateral tail vein or S.c. into the right leg. After 24 hours, different organs were harvested and assayed in a luciferase organ assay. Luciferase expression is compared with a control naive mouse. Luciferase expression at the injection site was only assayed for animals injected s.c. with luciferase-expressing DCs. Continuous luciferase expression at 24 and 48 hours by the injected DCs was demonstrated by keeping an aliquot of the injected DCs in in vitro culture, after which close to $1 \times 10^{6}$ light units per $10^{6}$ DCs was expressed.

$8.9 \mathrm{~mm}$ (Table 2 and Fig 5). This effect was evident as early as 48 hours after DC administration. A greater antitumor effect was observed in groups of mice with tumors of smaller diameter. Complete tumor regressions were rare; only 5 were seen in a total of 75 treated mice (7\%). All of the control mice developed progressively growing tumors (tumor regressions in 5 of 75 mice versus 0 of 75 mice, respectively, $P=$ NS, Table 2). In these five mice, the initial tumor diameter was $<3 \mathrm{~mm}$. Treatment with untransduced DCs had no significant effect on NFSA(MART1) tumor growth (Fig 5). The effect of additional DC administrations to mice with established tumors was assessed. In two studies, treating macroscopically established tumors with two weekly DC administrations did not improve the antitumor effect of the initial AdVMART1/DC administration (Fig 6a and Table 2).

Tumor infiltration by DCs has been correlated with increased survival in some human cancers. ${ }^{17}$ To explore the effect of increasing the number of functional APCs inside the tumor, the effect of an intratumoral (i.t) injection of AdVMART1/DCs was compared with an i.v. injection. In two separate studies, an i.t. injection of AdVMART1/DCs did not increase the effect of the systemic administration of MART-1-expressing DCs (Fig $6 \mathrm{~b}$ and Table 2).

\section{Treatment of established pulmonary metastases}

MART-1-transduced DCs were used to treat 1-week established pulmonary metastases. Mice not treated with DCs develop multiple pulmonary metastases 15 days after i.v. injection of $1 \times 10^{6}$ NFSA(MART1) tumor cells. Mice treated on day 7 after pulmonary seeding with untransduced DCs given i.v. showed a significant decrease in pulmonary nodules compared with the control group (106.0 vs. $174.4, P=.03$ ). However, an even greater reduction in pulmonary metastases was observed with AdVMART1/DC treatment on day 7 (60.2 vs. $174.4, P=.0002)$. Similar results were observed in two other separate studies in which mice were injected with $1 \times 10^{5}$ or $5 \times 10^{5}$ NFSA(MART1) tumor cells on day 0 (Table 3).

Table 2. Summary of Studies in which Established s.c. Tumors Were Treated with AdVMART1/DCs

\begin{tabular}{|c|c|c|c|c|c|c|c|}
\hline Study no. & $\mathrm{Tx}^{*}$ day & $\begin{array}{l}\text { Mean initial } \\
\text { diameter } \\
(\mathrm{mm})\end{array}$ & \multicolumn{2}{|c|}{ Mean final diameter (mm) } & $P$ & \multicolumn{2}{|c|}{ No. tumor regressions/total } \\
\hline $1 \mathrm{a}$ & 13 & $2.2 \pm 0.6$ & $7.8 \pm 2.9$ & $19.2 \pm 1.2$ & 0.008 & $2 / 5$ & $0 / 5$ \\
\hline 2 & $11+18$ & $3.2 \pm 1.0$ & $11.7 \pm 1.9$ & $21.0 \pm 1.6$ & 0.01 & $0 / 5$ & $0 / 5$ \\
\hline 3 & $9+16$ & $2.0 \pm 0.3$ & $7.5 \pm 2.7$ & $18.8 \pm 0.5$ & 0.004 & $1 / 5$ & $0 / 5$ \\
\hline 4 & 14 & $5.1 \pm 0.8$ & $13.0 \pm 1.3$ & $18.6 \pm 0.6$ & 0.005 & $0 / 5$ & $0 / 5$ \\
\hline $7 a$ & 9 & $2.9 \pm 0.4$ & $10.9 \pm 1.6$ & $16.4 \pm 1.4$ & 0.03 & $0 / 5$ & $0 / 5$ \\
\hline $7 \mathrm{~b}$ & $9+16$ & $2.7 \pm 0.6$ & $6.7 \pm 1.8$ & $16.4 \pm 1.4$ & 0.007 & $1 / 5$ & $0 / 5$ \\
\hline $8 a$ & 8 & $1.6 \pm 0.2$ & $8.7 \pm 1.0$ & $18.1 \pm 1.2$ & 0.0008 & $0 / 5$ & $0 / 5$ \\
\hline $8 b$ & $8+15$ & $1.5 \pm 0.3$ & $8.2 \pm 0.8$ & $18.1 \pm 1.2$ & 0.0002 & $0 / 5$ & $0 / 5$ \\
\hline $9 a$ & 11 (i.v.) & $3.8 \pm 0.7$ & $13.6 \pm 1.4$ & $18.4 \pm 1.3$ & 0.03 & $0 / 5$ & $0 / 5$ \\
\hline $9 b$ & 11 (i.t.) & $3.3 \pm 0.4$ & $13.8 \pm 1.6$ & $18.4 \pm 1.3$ & 0.05 & $0 / 5$ & $0 / 5$ \\
\hline
\end{tabular}

${ }^{*}$ Tx, treatment. 

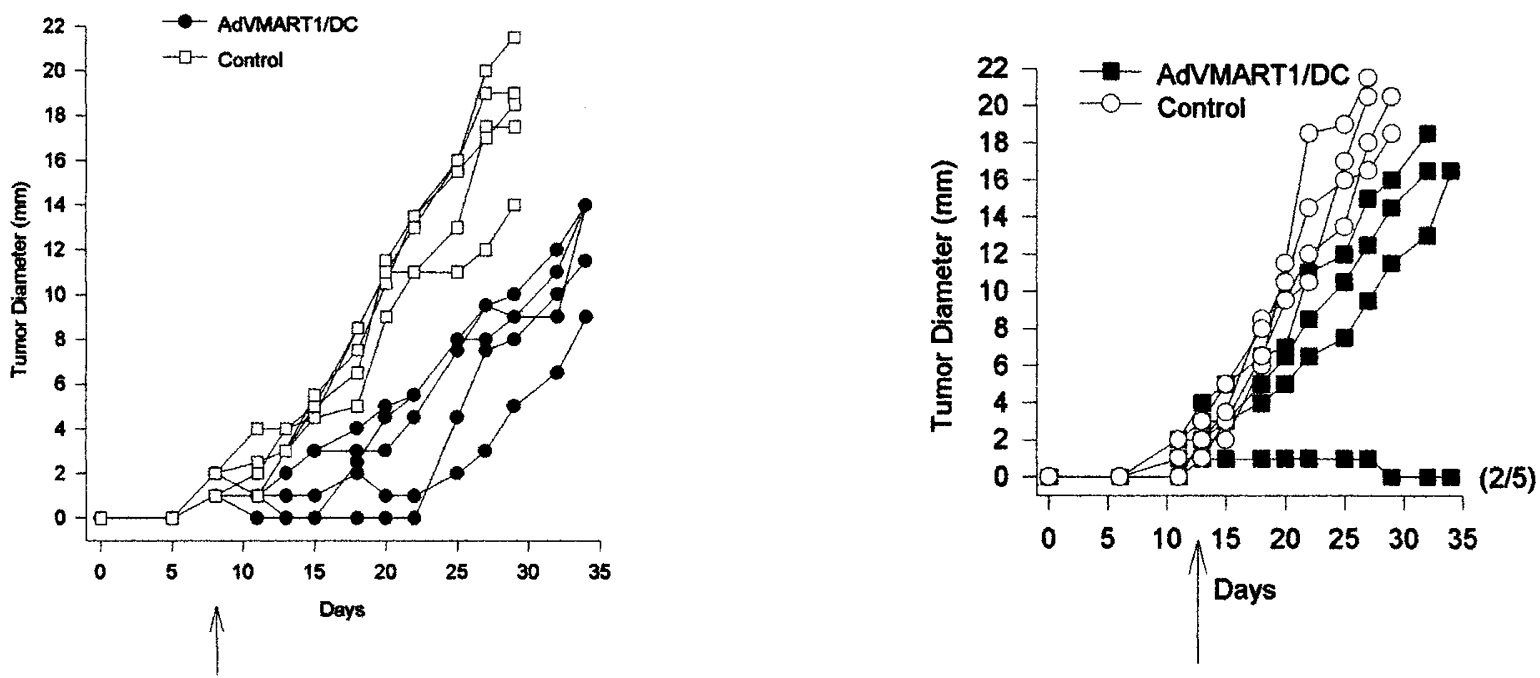

c
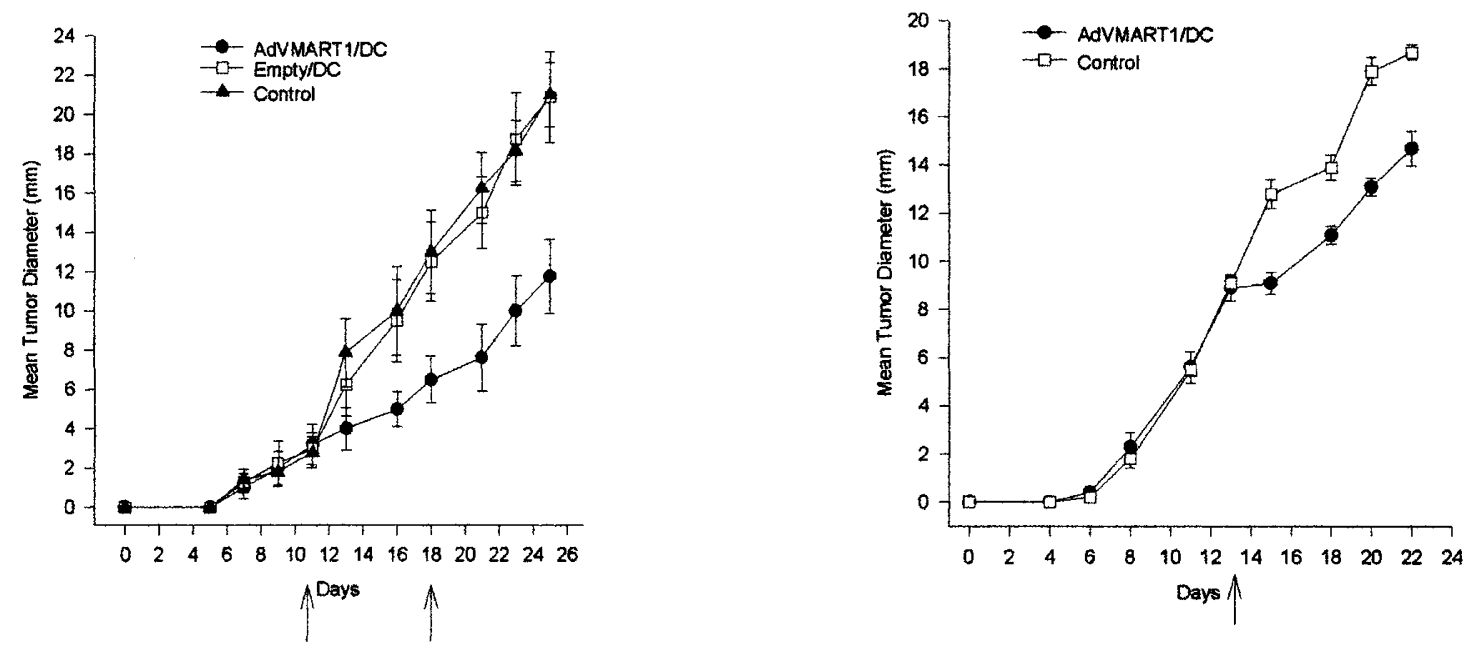

Figure 5. Treatment of macroscopic tumors with AdVMART1/DCs. Tumor growth in individual mice with NFSA(MART1) tumors implanted on the left flanks at day 0 and treated with AdVMART1/DCs on days 8 (a) and 13 (b) is shown. Mean tumor growth in animals treated on days 11 and 18 (c) as well as rapidly growing NFSA(MART1) tumors treated on day 13 (d) are also shown. 

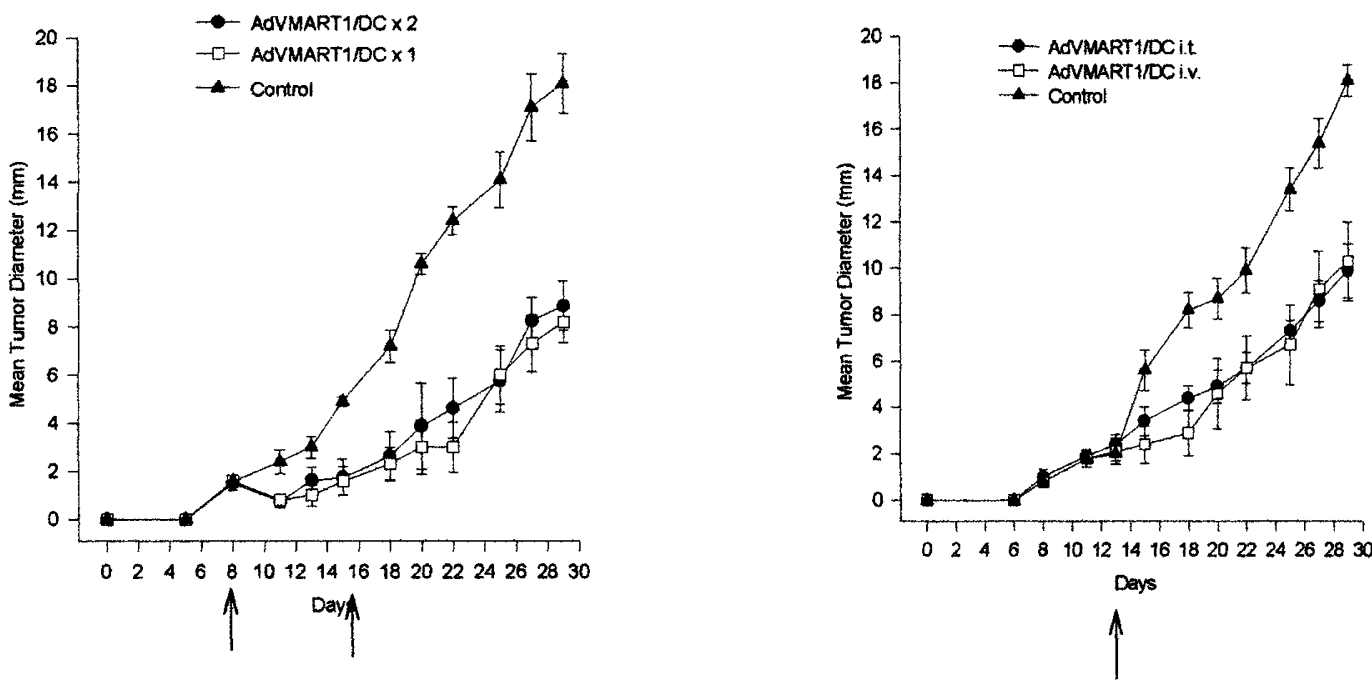

Figure 6. Treatment of macroscopic tumors with AdVMART1/DCs administered by different schedules. a: Mice with similar size tumors were randomized on day 8 to one or two AdVMART1/DC treatments and compared with an untreated control group. b: Mice with similar size tumors were randomized on day 13 to a single AdVMART1/DC treatment administered i.v. or i.t. and were compared with an untreated control group.

\section{T-cell subpopulation analysis}

The contribution of T-cell subpopulations to the tumor protection was assessed by in vivo depletion of $\mathrm{CD}^{+}$or $\mathrm{CD} 8^{+}$lymphocytes using purified mAbs. Successful depletion was monitored by flow cytometry on the day of tumor challenge. As shown in Figure 7, in vivo blocking of either CD4 or CD8 T-cell subpopulations significantly abrogated the antitumor protection generated by AdVMART1/DC vaccination; this finding was confirmed in two replicate experiments. A histological examination of NFSA(MART1) tumors from naive mice showed no lymphocytic infiltration using standard hematoxylin-eosin staining. Animals with measurable tumors treated i.v. with MART-1-transduced DCs had areas of modest peritumor lymphocytic infiltration, with a few lymphocytes within the tumor mass. Immunohistochemical staining revealed that these infiltrating lymphocytes con- sisted of cells from both CD8 and CD4 T-cell subtypes (data not shown).

Cytokine profile by in vitro-restimulated splenocytes from MART-1-immunized animals

Spleen cells obtained from MART-1-immunized and unimmunized mice were restimulated in vitro with irradiated NFSA(MART1) for 5 days, after which time cytokine mRNA production was measured by RT-PCR. Splenocytes from mice immunized with AdVMART1/ DCs synthesized higher levels of IL-2 and IFN- $\gamma$ mRNA by RT-PCR compared with mice immunized with nontransduced DCs or DCs transduced with the empty AdV vector AdVRR5, consistent with the induction of a $T$ helper type 1 (Th1) profile. In two separate experiments, in vitro-restimulated splenocytes also produced higher mRNA levels of the Th2 cytokine IL-4 compared with

Table 3. Number of Pulmonary Metastases 15 Days After i.v. Tumor Injection

\begin{tabular}{lcccc}
\hline Study no. & No. tumor cells & Control & Empty DCs & AdVMART1/DCs \\
\hline 1 & $1 \times 10^{5}$ & $34.6 \pm 6.7$ & $19.0 \pm 5.4$ & $14.6 \pm 3.7^{*}$ \\
2 & $5 \times 10^{5}$ & $60.6 \pm 7.9$ & $48.6 \pm 8.2$ & $24.6 \pm 5.3 \dagger$ \\
3 & $1 \times 10^{6}$ & $174.4 \pm 11.1$ & $106.0 \pm 23.3 \ddagger$ & $60.2 \pm 13.8 \S$ \\
\hline
\end{tabular}

Mice were injected i.v. on day 0 with different numbers of live NFSA(MART1) tumor cells. On day 7 , groups of five mice received treatment with $5 \times 10^{5}$ untransduced (empty) DCs or AdVMART1/DCs, or received no treatment (control). On day 15, lungs were harvested. Animals with $>200$ pulmonary metastases were considered too numerous to count, and were recorded as having 200 pulmonary metastases. Significant differences can be observed.

*Study 1: AdVMART1/DCs versus control, $P=.03$.

†Study 2: AdVMART1/DCs versus control, $P=.008$; AdVMART1/DC versus empty DCs, $P=.04$.

¥Study 3: Empty DCs versus control, $P=.03$.

§Study 3: AdVMART1/DCs versus control, $P=.0002$. 


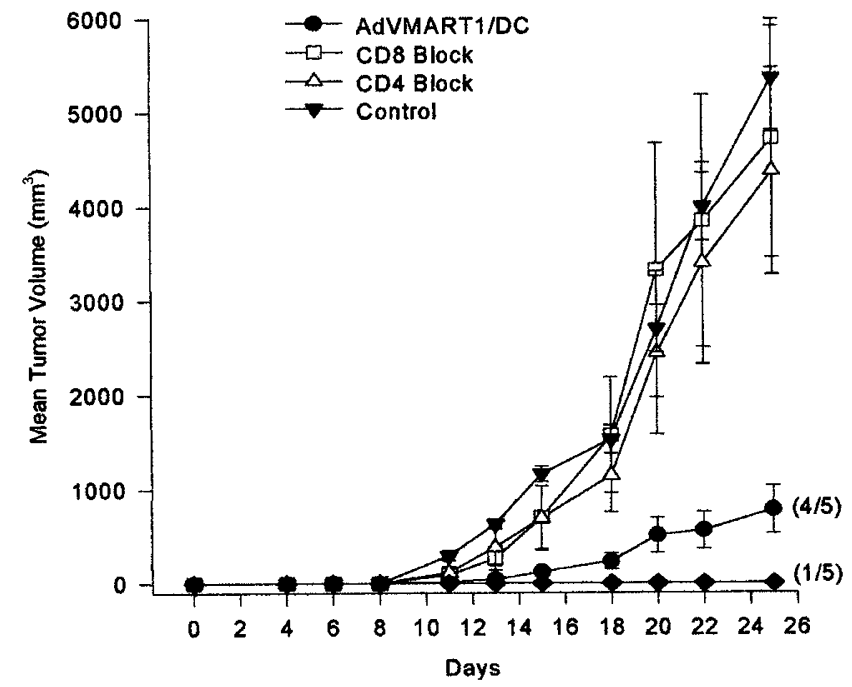

Figure 7. In vivo blocking of CD4/CD8 T-cell subsets. Three groups of five mice were immunized twice with $5 \times 10^{5}$ AdVMART1/DCs $(\mathrm{MOI}=100)$. On days 5,3 , and 1 before tumor challenge with $1 \times$ $10^{6}$ NFSA(MART1) cells, mice from two immunized groups were treated i.p. with CD4 or CD8 neutralizing Abs. Ab treatment was repeated every 6 days until completion of the study. Tumor growth is compared with an unimmunized control group. CD4 and CD8 treatment abrogated the protective effect of AdVMART1/DC treatment $(P=.02$ and $P=.01$, respectively).

splenocytes from naive mice or mice immunized with the irrelevant AdVRR5 vector. The expression of IL-10 was equal in restimulated splenocytes from naive, AdVRR5/ DC-immunized, and AdVMART1/DC-immunized mice (Fig 8).

Cytokine production was quantitated at a cellular level using an ELISPOT assay for a Th1 (IFN- $\gamma$ ) and a Th2 (IL-4) cytokine. SVEC(MART1) in vitro-restimulated splenocytes from immunized and unimmunized mice were added to Ab-precoated wells, and the number of cytokine-producing spot-forming colonies were counted after a 24-hour incubation. In one study that was representative of three independent studies, AdVMART1/DC-immunized mice had 1/426 MART-1specific IFN- $\gamma$-producing precursors, whereas mice immunized with untransduced DCs and unimmunized mice had 1/1960 and 1/25,641 precursors, respectively (Fig 9). A similar trend was found with IL-4-producing cells, where splenocytes from AdVMART1/DC-immunized mice produced more spots than splenocytes from untransduced DCs or control mice.

\section{Induction of cytotoxic T lymphocytes (CTLs) in vitro and cytotoxicity assays}

Splenocytes were harvested from immunized and nonimmunized mice 1 week after two weekly AdVMART1/DC injections and were restimulated in vitro with irradiated SVEC(MART1) or NFSA(MART1) in the presence of $10 \mathrm{U} / \mathrm{mL}$ of recombinant human IL-2. After 4 days, the ability of splenocytes to lyse chromated NFSA(MART1) targets was assessed in a standard
A

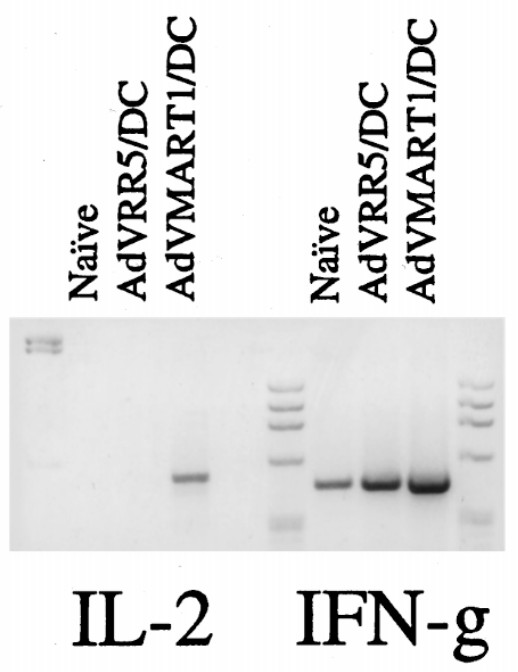

B

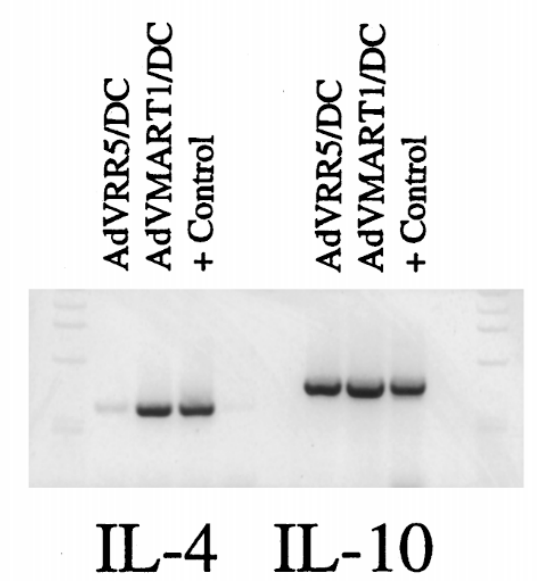

Figure 8. PCR analysis of cytokine mRNA expression in in vitrorestimulated splenocytes. Splenocytes from naive mice and mice immunized twice i.v. with AdVRR5/DCs or AdVMART1/DCs were harvested and restimulated in vitro for 5 days with irradiated NFSA(MART1) cells (without IL-2). Total RNA was isolated, reverse transcribed, and amplified with different cytokine primers. The amount of DNA per line was semiquantitated with the housekeeping murine gene APRT, and equivalent amounts of the reverse-transcribed product were loaded for each PCR sample. Expected bands are: IL-2, 502 base pairs (bp); IFN- $\gamma, 460$ bp; IL-4, 357 bp; and IL-10, $455 \mathrm{bp}$.

4-hour chromium release assay. In four separate studies, spleens from AdVMART1/DC-immunized mice had MART-1-specific CTLs when restimulated with either SVEC(MART1) or NFSA(MART1) (Fig 10). NFSA(MART1) lysis was blocked by an MHC class I neutralizing Ab. This CTL activity was not inhibited by cold Yac-1 (NK) targets.

\section{DISCUSSION}

DCs are highly potent APCs. ${ }^{3}$ Tumor-specific immunity to experimental tumors can be generated by the in vivo 


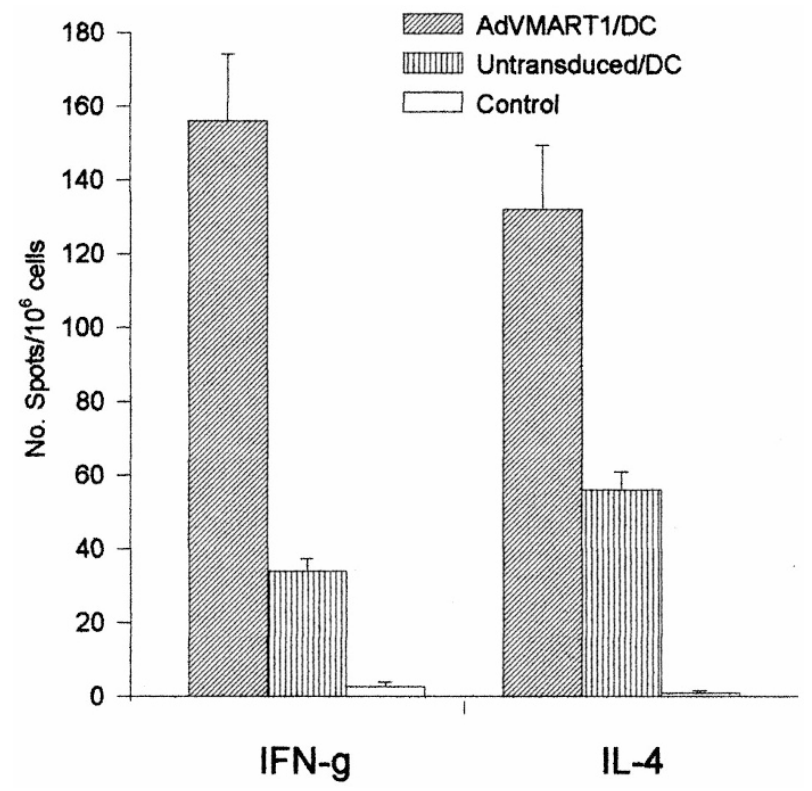

Figure 9. Cytokine production by ELISPOT assay. Mice were immunized twice i.v. with AdVMART1/DCs or untransduced DCs or were not immunized; splenocytes were restimulated in vitro with MART-1-expressing cells. Their ability to produce IFN- $\gamma$ and IL-4 was assessed after a 24-hour incubation in Ab-coated plates. Spots were visualized using a secondary biotin-labeled Ab. Results represent the mean \pm SEM of triplicate wells. Significant differences for IFN- $\gamma$ production were found between AdVMART1/DCs and untransduced DCs $(P=.003)$ and control mice $(P=.001)$. For IL-4 production, differences were found between AdVMART1/DCs and untransduced DCs $(P=.02)$ and control mice (0.001).

administration of DCs pulsed with defined synthetic peptide epitopes, tumor cell lysates, acid-eluted tumor cell surface peptides, or tumor Ag RNA. ${ }^{18-26}$ Recent strategies have focused on genetically engineered DCs to express cloned tumor Ag genes. ${ }^{9,10,27,28}$ Engineering DCs to express an entire tumor $\mathrm{Ag}$ gene has several potential advantages: (a) the continuous expression of antigenic peptides by MHC molecules, ${ }^{10,27,29}$ (b) the potential for both MHC class I and class II epitope presentation, ${ }^{10,27,29-31}$ (c) the simultaneous presentation of multiple $\mathrm{Ag}$-derived epitopes ${ }^{32}$ reducing the potential risk of escape mutant tumor cells, ${ }^{33,34}$ and (d) the potential for $\mathrm{Ag}$ presentation regardless of MHC allele. ${ }^{35}$

We developed a murine model to test DC-based genetic immunotherapy strategies. We selected a nonimmunogenic fibrosarcoma cell line (NFSA) that is syngeneic in $\mathrm{C} 3 \mathrm{H}\left(\mathrm{H}-2^{\mathrm{k}}\right)$ mice and derived a stably transfected variant expressing the human MART-1 melanoma Ag (NFSA(MART1)). Not too surprisingly, NFSA(MART1) is, at best, poorly immunogenic despite the expression of a human melanoma Ag. Attempts to immunize mice with irradiated NFSA(MART1) did not generate significant protective immunity. In studies using this model that have been reported previously, ${ }^{9}$ several weekly intramuscular injections of plasmid DNA eucaryotic expression vector for MART-1 did induce intermediate levels of partial protection. Because DNAbased immunization is now known to require the participation of host APCs, we hypothesized that DCs directly engineered to express the MART-1 Ag might provide for the generation of superior immunity.

As a preamble to developing this model, we gained experience in introducing DNA into murine and human DCs. As we reported previously, ${ }^{36}$ these cells are resistant to many standard physical methods of transfection, such as calcium phosphate, cationic liposomes, or electroporation. However, we found that recombinant adenoviral vectors provided for high levels of gene expression and constructed an E1-deleted AdV vector expressing the MART-1 gene product. ${ }^{9}$ Other investigators have reported success in transducing DCs with retroviral vectors, ${ }^{37}$ adeno-associated viral vectors, ${ }^{38}$ plasmid DNA delivered biolistically or through particlemediated endocytosis, ${ }^{39}$ and transcribed mRNA. ${ }^{24} \mathrm{Al}-$ though DCs transduced with E1-deleted AdV vectors could be expected to express immunogenic viral peptide epitopes, Brossart et $\mathrm{al}^{10}$ demonstrated that the repeated administration of AdV-transduced DCs could be used to elicit antitumor immunity to a model tumor $\mathrm{Ag}$ without the generation of high levels of neutralizing antiviral Abs. However, there is the possibility that AdV immunogenicity may contribute to the decreased protection with repeated AdVMART1/DC vaccinations found in our studies. We have addressed this possibility in separate studies, and found that two to four vaccinations with DCs transduced with the empty adenoviral vector AdVRR5 do not preclude a successful immunization with a subsequent single vaccination with AdVMART1/ DCs. The anti-MART-1 response obtained in the mice exposed previously to adenoviral epitopes is comparable with the response seen for mice receiving a single AdVMART1/DC vaccination (A.R., unpublished observations).

Our studies indicate that a DC dose in a range between $1 \times 10^{5}$ and $1 \times 10^{6}$ per animal and an MOI between 3 and 100 are effective for vaccination, and that the routes of immunization do not significantly affect the antitumor protection. The results of vaccination data by us and others ${ }^{25,27,28}$ are in accord with the hypothesis that Ag-presenting DCs or the epitopes they present do not need to be present in large numbers for the initiation of a T-cell response. ${ }^{3}$ In several animal models, ${ }^{25,27,28}$ a single vaccination with DC-based vaccines has been shown to generate effective tumor protection, and Specht et $\mathrm{a}^{27}$ have shown that increasing the dose of genetically engineered DCs to vaccinate mice against a model tumor Ag did not further enhance antitumor activity. Indeed, there may be a threshold effect rather than a dose-response effect when using DC-based strategies.

Our reproducible observation that five immunizations are worse than one in this protection model is intriguing, and is the focus of current efforts. Repeated AdV/DC vaccinations may skew T-cell responses toward a Th2 response. ${ }^{40,41}$ Alternatively, the continuing Ag stimulation may drive Ag-reactive T cells into apoptotic pro- 
Figure 10. Lysis of MART-1-expressing targets by CTLs from mice immunized with AdVMART1/DCs. Splenocytes were harvested, restimulated in vitro for 4 days, and mixed in graduated doses with $1 \times$ $10^{4}{ }^{51} \mathrm{Cr}$-labeled target cells. Cells were incubated for 4 hours at $37^{\circ} \mathrm{C}$ in a $5 \%$ humidified incubator. The ${ }^{51} \mathrm{Cr}$ release from the lysed target cells was measured. a: NFSA(MART1) lysis by splenocytes from tumor-free mice immunized twice with AdVMART1/DCs or empty DCs or from unimmunized mice; splenocytes were restimulated in vitro with irradiated SVEC(MART1). b: NFSA(MART1) or Yac-1 lysis of SVEC(MART1)-restimulated splenocytes from AdVMART1/DC-immunized mice cultured in the presence of a $40 \times$ excess of cold Yac- 1 cells. c,d: NFSA(MART1) lysis by splenocytes of MART-1-treated or untreated tumor-bearing mice. DC treatment was done 6 days after tumor implantation, and splenocytes were harvested 7 days later. At the time of splenocyte harvest, tumors had a diameter of $3 \mathrm{~mm}$ (AdVMART1/ DCs), $7.5 \mathrm{~mm}$ (empty DCs), or $8 \mathrm{~mm}$ (controls). Splenocytes were restimulated in vitro with irradiated SVEC(MART1) (c) or NFSA(MART1) (d).

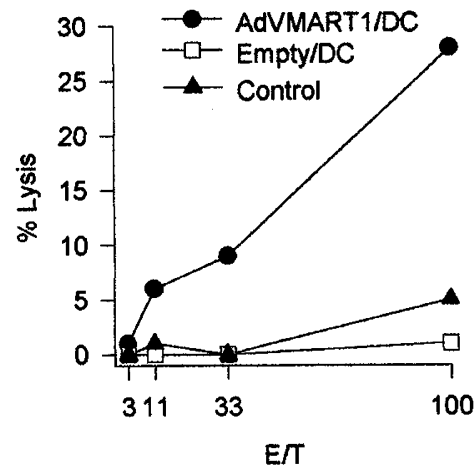

c

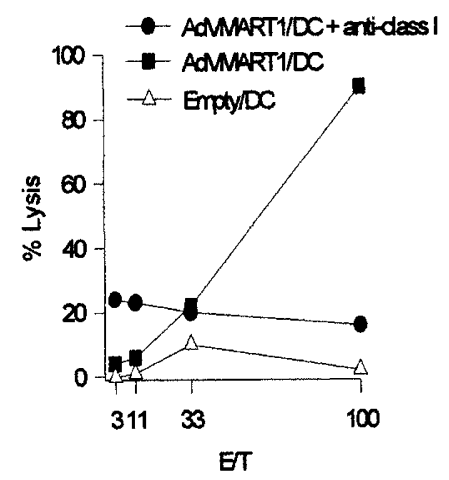

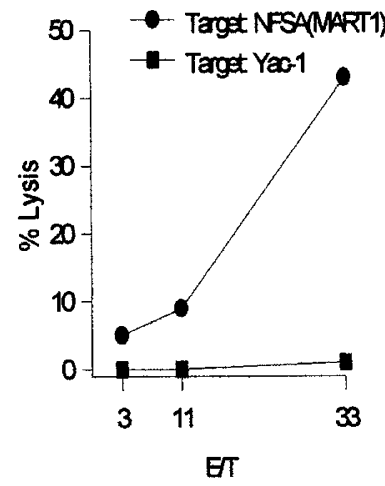

d grammed cell death. ${ }^{42,43}$ This interesting finding should add a cautionary note to simplistic interpretations of DC-based immunotherapies.

DCs administered s.c. or i.v. interact with the immune system within different organs but appear to be comparable in immune induction. Our results concur with those of Nair et al, ${ }^{25}$ who reported that different routes of immunization did not greatly affect the level of cytotoxicity generated. Cultured DCs transduced with the luciferase gene were found in the draining LNs after s.c. injection and in lungs and spleen after i.v. administration. In a study in chimpanzees, DCs injected s.c. were also detected in the draining LNs 24 hours after administration. ${ }^{44}$ The LN tropism of murine DCs injected s.c. has also been described previously. ${ }^{45-47}$ However, after i.v. administration, Kupiec-Weglinski et $\mathrm{al}^{45}$ reported that freshly isolated murine DCs are only transiently found in the lungs and then migrate primarily to the spleen and liver. The use of different DC populations, more sensitive and nonimmunogenic DC markers, and long-term studies would be worthwhile to define the in vivo biology of ex vivo-manipulated DCs.

Mice with established s.c. tumors or pulmonary metastases had significant reductions in tumor growth rate with systemic AdVMART1/DC vaccination. Although occasional very small s.c. tumors regressed completely, a transient delay in tumor growth with resumption of a similar growth curve was most commonly observed. Remarkably, this effect was apparent within 24-48 hours and was not seen with DC administration alone. Clear-cut but unimpressive peritumor and i.t. CD8 and CD4 lymphocytic infiltrates were noted in AdVMART1/ 
DC-treated mice. Other investigators have observed complete regressions of established tumors using DCs pulsed with acid-eluted peptides. ${ }^{22}$ These impressive results must be due, in part, to the use of fairly immunogenic tumor models. ${ }^{48}$ Defining methods to improve DC-based treatments of established poorly immunogenic tumors such as NFSA(MART1) is another area of current investigation.

Although these studies demonstrate an absolute requirement for CD8 and CD4 T-cell subsets, they by no means provide direct evidence that MHC class I- or II-associated MART-1 epitopes are expressed by transduced DCs. Cross-priming (the uptake and presentation of tumor Ag by host APCs) could be taking place, but this would not explain the requirement for DCs as opposed to other APCs for effective immunization. Direct evidence of MHC class I presentation by MART1-transduced DCs comes from our studies with human HLA-A2.1 DCs, which express the HLA-A2.1-restricted MART- $1_{27-35}$ immunodominant peptide and can generate MART- 1 peptide-specific CD8 ${ }^{+}$CTLs in vitro from naive A2.1 donors. ${ }^{49}$ In addition, AdVMART-1-transduced human DCs also generated MART-1-specific $\mathrm{CD}^{+}$cytokine-producing cells, which suggests that, in this in vitro human system, human DCs transduced with AdVMART1 express MART-1-derived epitopes in MHC class II molecules. ${ }^{50}$

Human MART-1 is a xenoantigen in this mouse model, which means that it is not directly relevant to the possibility of using this vaccination strategy to break tolerance to MART-1 in human melanoma patients. However, in another mouse model in C57BL/6 mice, we have successfully used human MART-1 to vaccinate against the murine B16 melanoma, which endogenously expresses the murine counterpart of MART-1. ${ }^{51}$ In another in vivo model, we have generated splenic CTLs and IFN- $\gamma$-producing cells specific for human MART-1 from HLA-A2.1-transgenic mice immunized with AdVMART1/DCs (A.R., unpublished observations). Taken together, our animal models and human laboratory work ${ }^{50,51}$ suggest that AdVMART1/DC vaccination is a promising strategy to attempt to generate protective MART-1 immunity in patients with melanoma.

Finally, we were able to measure the Th1/Th2-type cytokine responses in the splenocytes (using RT-PCR and ELISPOT). These in vitro correlates may aid efforts to understand the immunobiology of these events and improve on AdVMART1/DC-generated immunity. Measures that have been successful in other tumor immunotherapy models include the skewing of responses toward a Th1-type response with IL-12 DC transfection $^{39}$ or the inhibition of Th2 cytokines with neutralizing Abs. ${ }^{22,48}$

In conclusion, MART-1 genetically engineered DCs can effectively vaccinate mice against a tumor challenge with MART-1-expressing tumors. The antitumor protection is MART-1-specific, involves both $\mathrm{CD}^{+}$and $\mathrm{CD} 8^{+}$ $\mathrm{T}$ cells, and is associated with the up-regulation of both Th1- and Th2-type cytokines.

\section{ACKNOWLEDGMENTS}

We thank Drs. Duan-Ren Weng, Rong-Rong Huang, and Alistair J. Cochran for outstanding immunohistochemical work. This work was supported in part by National Institutes of Health/National Cancer Institute Grants PO1 CA5926, T32 CA091220, T32 CA75956, and K12 CA76905, and by the Monkarsh and Kesselman Funds. A.R. was supported by a fellowship from the Fondo de Investigación Sanitaria 97/5458.

\section{REFERENCES}

1. Kripke ML. Antigenicity of murine skin tumors induced by ultraviolet light. J Natl Cancer Inst. 1974;53:1333-1336.

2. Speiser DE, Sebzda E, Ohteki T, et al. Tumor necrosis factor receptor p55 mediates deletion of peripheral cytotoxic T lymphocytes in vivo. Eur J Immunol. 1996;26:30553060 .

3. Steinman RM. The dendritic cell system and its role in immunogenicity. Annu Rev Immunol. 1991;9:271-296.

4. Schuler G, Steinman RM. Dendritic cells as adjuvants for immune-mediated resistance to tumors. J Exp Med. 1997; 186:1183-1187.

5. Nanda NK, Sercarz EE. Induction of anti-self-immunity to cure cancer. Cell. 1995;82:13-17.

6. Coulie PG, Brichard V, Van Pel A, et al. A new gene coding for a differentiation antigen recognized by autologous cytolytic T lymphocytes on HLA-A2 melanomas. $J$ Exp Med. 1994;180:35-42.

7. Kawakami Y, Eliyahu S, Delgado $\mathrm{CH}$, et al. Cloning of the gene coding for a shared human melanoma antigen recognized by autologous T cells infiltrating into tumor. Proc Natl Acad Sci USA. 1994;91:3515-3519.

8. de Vries TJ, Fourkour A, Wobbes T, et al. Heterogeneous expression of immunotherapy candidate proteins gp100, MART-1, and tyrosinase in human melanoma cell lines and in human melanocytic lesions. Cancer Res. 1997;57: 3223-3229.

9. Ribas A, Butterfield LH, McBride WH, et al. Genetic immunization for the melanoma antigen MART-1/ Melan-A using recombinant adenovirus-transduced murine dendritic cells. Cancer Res. 1997;57:2865-2869.

10. Brossart P, Goldrath AW, Butz EA, et al. Virus-mediated delivery of antigenic epitopes into dendritic cells as a means to induce CTL. J Immunol. 1997;158:3270-3276.

11. Milas L, Wike J, Hunter N, et al. Macrophage content of murine sarcomas and carcinomas: associations with tumor growth parameters and tumor radiocurability. Cancer Res. 1987;47:1069-1075.

12. Volpe JP, Hunter N, Basic I, et al. Metastatic properties of murine sarcomas and carcinomas: positive correlation with lung colonization and lack of correlation with s.c. tumor take. Clin Exp Metastasis. 1985;3:281-294.

13. Inaba K, Inaba M, Romani N, et al. Generation of large numbers of dendritic cells from mouse bone marrow cultures supplemented with granulocyte/macrophage colony-stimulating factor. J Exp Med. 1992;176:1693-1702.

14. Toloza EM, Hunt K, Swisher S, et al. In vivo cancer gene therapy with a recombinant interleukin-2 adenovirus vector. Cancer Gene Ther. 1996;3:11-17.

15. Bui LA, Butterfield LH, Kim JY, et al. In vivo therapy of hepatocellular carcinoma with a tumor-specific adenoviral vector expressing interleukin-2. Hum Gene Ther. 1997;8: 2173-2182.

16. Brugert H, Kvist S. An adenovirus type 2 glycoprotein 
blocks cell surface expression of human histocompatibility class I antigens. Cell. 1985;41:987.

17. Lotze MT. Getting to the source: dendritic cells as therapeutic reagents for the treatment of patients with cancer. Ann Surg. 1997;226:1-5.

18. Mayordomo JI, Zorina T, Storkus WJ, et al. Bone marrowderived dendritic cells pulsed with synthetic tumour peptides elicit protective and therapeutic antitumour immunity. Nat Med. 1995;1:1297-1302.

19. Mayordomo JI, Loftus DJ, Sakamoto H, et al. Therapy of murine tumors with p53 wild-type and mutant sequence peptide-based vaccines. J Exp Med. 1996;183:1357-1365.

20. Porgador A, Gilboa E. Bone marrow-generated dendritic cells pulsed with a class I-restricted peptide are potent inducers of cytotoxic T lymphocytes. J Exp Med. 1995;182: 255-260.

21. Paglia P, Chiodoni C, Rodolfo M, et al. Murine dendritic cells loaded in vitro with soluble protein prime cytotoxic $\mathrm{T}$ lymphocytes against tumor antigen in vivo. $J$ Exp Med. 1996;183:317-322.

22. Zitvogel L, Mayordomo JI, Tjandrawan T, et al. Therapy of murine tumors with tumor peptide-pulsed dendritic cells: dependence on T cells, B7 costimulation, and T helper cell 1-associated cytokines. J Exp Med. 1996;183:87-97.

23. Celluzzi CM, Mayordomo JI, Storkus WJ, et al. Peptidepulsed dendritic cells induce antigen-specific CTL-mediated protective tumor immunity. J Exp Med. 1996;183:283287.

24. Boczkowski D, Nair SK, Snyder D, et al. Dendritic cells pulsed with RNA are potent antigen-presenting cells in vitro and in vivo. J Exp Med. 1996;184:465-472.

25. Nair SK, Snyder D, Rouse BT, et al. Regression of tumors in mice vaccinated with professional antigen-presenting cells pulsed with tumor extracts. Int J Cancer. 1997;70:706715 .

26. Ashley DM, Faiola B, Nair S, et al. Bone marrowgenerated dendritic cells pulsed with tumor extracts or tumor RNA induce antitumor immunity against central nervous system tumors. J Exp Med. 1997;186:1177-1182.

27. Specht JM, Wang G, Do MT, et al. Dendritic cells retrovirally transduced with a model antigen gene are therapeutically effective against established pulmonary metastases. J Exp Med. 1997;186:1213-1221.

28. Song W, Kong HL, Carpenter H, et al. Dendritic cells genetically modified with an adenovirus vector encoding the cDNA for a model antigen induce protective and therapeutic antitumor immunity. J Exp Med. 1997;186: 1247-1256.

29. Kim CJ, Prevette T, Cormier J, et al. Dendritic cells infected with poxviruses encoding MART-1/Melan A sensitize T lymphocytes in vitro. J Immunother. 1997;20:276286.

30. Smith CA, Woodruff LS, Kitchingman GR, et al. Adenovirus-pulsed dendritic cells stimulate human virus-specific T-cell responses in vitro. J Virol. 1996;70:6733-6740.

31. Yee C, Gilbert MJ, Riddell SR, et al. Isolation of tyrosinase-specific $\mathrm{CD}^{+}$and $\mathrm{CD}^{+} \mathrm{T}$ cell clones from the peripheral blood of melanoma patients following in vitro stimulation with recombinant vaccinia virus. J Immunol. 1996; $157: 4079-4086$.

32. van Elsas A, van der Burg SH, van der Minne CE, et al. Peptide-pulsed dendritic cells induce tumoricidal cytotoxic $\mathrm{T}$ lymphocytes from healthy donors against stably HLAA*0201-binding peptides from the Melan-A/MART-1 self antigen. Eur J Immunol. 1996;26:1683-1689.
33. Van Waes C, Monach PA, Urban JL, et al. Immunodominance deters the response to other tumor antigens thereby favoring escape: prevention by vaccination with tumor variants selected with cloned cytolytic $\mathrm{T}$ cells in vitro. Tissue Antigens. 1996;47:399-407.

34. Jager E, Ringhoffer M, Altmannsberger M, et al. Immunoselection in vivo: independent loss of MHC class I and melanocyte differentiation antigen expression in metastatic melanoma. Int J Cancer. 1997;71:142-147.

35. Fleischhauer K, Fruci D, Van Endert P, et al. Characterization of antigenic peptides presented by HLA-B44 molecules on tumor cells expressing the gene MAGE-3. Int J Cancer. 1996;68:622.

36. Arthur JF, Butterfield LH, Roth MD, et al. A comparison of gene transfer methods in human dendritic cells. Cancer Gene Ther. 1997;4:17-25.

37. Reeves ME, Royal RE, Lam JS, et al. Retroviral transduction of human dendritic cells with a tumor-associated antigen gene. Cancer Res. 1996;56:5672-5677.

38. Shaughnessy E, Lu D, Chatterjee S, et al. Parvoviral vectors for the gene therapy of cancer. Semin Oncol. 1996;23:159-171.

39. Zitvogel L, Couderc B, Mayordomo JI, et al. IL-12engineered dendritic cells serve as effective tumor vaccine adjuvants in vivo. Ann N Y Acad Sci. 1996;795:284-293.

40. Carter LL, Dutton RW. Relative perforin- and Fas-mediated lysis in T1 and T2 CD8 effector populations. J Immunol. 1995;155:1028-1031.

41. Hosken NA, Shibuya K, Heath AW, et al. The effect of antigen dose on $\mathrm{CD}^{+}{ }^{+} \mathrm{T}$ helper cell phenotype development in a T cell receptor- $\alpha \beta$-transgenic model. J Exp Med. 1995;182:1579-1584.

42. Scott DW, Grdina T, Shi Y. T cells commit suicide, but B cells are murdered! J Immunol. 1996;156:2352.

43. Green DR, Scott DW. Activation-induced apoptosis in lymphocytes. Curr Opin Immunol. 1994;6:476-487.

44. Barratt-Boyes SM, Watkins SC, Finn OJ. In vivo migration of dendritic cells differentiated in vitro: a chimpanzee model. J Immunol. 1997;158:4543.

45. Kupiec-Weglinski JW, Austyn JM, Morris PJ. Migration patterns of dendritic cells in the mouse: traffic from the blood, and $\mathrm{T}$ cell-dependent and -independent entry to lymphoid tissues. J Exp Med. 1988;167:632.

46. Inaba K, Steinman RM, Pack MW, et al. Identification of proliferating dendritic cell precursors in mouse blood. $J$ Exp Med. 1992;175:1157-1167.

47. Mayordomo JI, Zorina T, Storkus WJ, et al. Bone marrowderived dendritic cells serve as potent adjuvants for peptide-based antitumor vaccines. Stem Cells. 1997;15:94-103.

48. Hagenbaugh A, Sharma S, Dubinett SM, et al. Altered immune responses in interleukin 10 transgenic mice. J Exp Med. 1997;185:2101-2110.

49. Butterfield LH, Jilani SM, Chakraborty NG, et al. Generation of melanoma-specific CTLs by dendritic cells transduced with a MART-1 adenovirus. J Immunol. 1998;161: 5607-5613.

50. Perez-Diez A, Butterfield LH, Li L. Generation of CD8 ${ }^{+}$ and $\mathrm{CD}^{+} \mathrm{T}$ cell responses to dendritic cells genetically engineered to express the MART-1/Melan-A gene. Cancer Res. 1998;58:5305-5309.

51. Zhai Y, Yang JC, Spiess P, et al. Cloning and characterization of the genes encoding the murine homologues of the human melanoma antigens MART1 and gp100. J Immunother. 1997;20:15-25. 